Case 4.-A man, aged 62, first seen in January, 1932; he complained of substernal pain radiating to both arms, of six years' duration. The pain was much more easily produced in the last year; moderate exercise, such as light digging, brought it on, and it lasted for two to three minutes. It was always relieved by rest. The left border of the heart was in the mid-clavicular line; there were no murmurs. Blood pressure: $180 / 90$. During the examination the patient had an attack, which he described as being rather worse than usual. It was relieved by twenty minutes' rest. He now keeps well with adequate rest. The electrocardiograms are reproduced in Fig. 4. (A) was taken during the attack and (B) following it. (A) shows a depression of the RT interval in all leads, particularly in Leads 2 and 3.

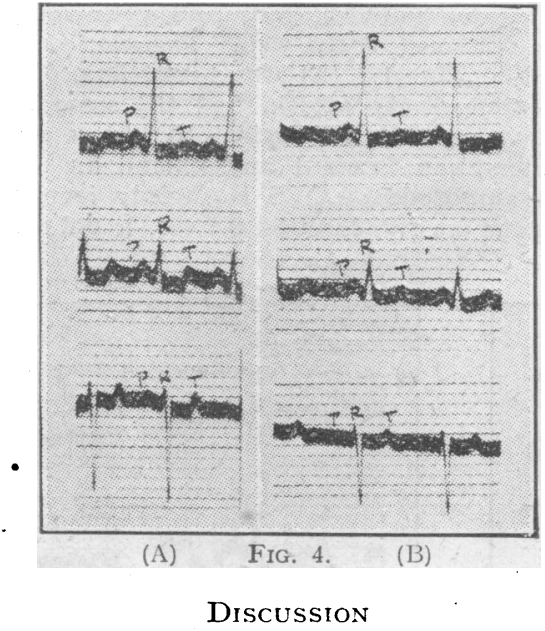

In these four cases definite changes in the ventricular complexes of the electrocardiograms are demonstrated. These changes resemble those produced by coronary thrombosis. It is agreed that they are not always present, due no doubt to " silent areas" in the myocardium, changes in which do not affect the electrocardiogram. The positive evidence adduced in the above cases and in those previously published points very strongly towards the coronary origin of anginal pain.

References

'Levine, Ernstene, and Jacobson: Arch. Int. Med., February, 1930, p. 191.

${ }^{2}$ Parkinson and Bedford: Lancet, 1931, i, 15

${ }^{3}$ Wood and Wolferth: Arch. Int. Med., March, 1931, p. 339.

The Italian Fascist National Federation Against Tuberculos:s has again placed at the disposal of the International Union Against Tuberculosis six scholarships at the Benito Mussolini Institute in Rome. The concitions submitted are as follows: These competitive scholarships, of a value of 6,000 lire respectively, plus board and lodging, are intended to enable foreign medical practitioners to stay at the Benito Mussolini Institute in Rome for the purpose of following a course of studies. This stage of eight months will correspond with the academic year (from November 15 th to July 15th), including the usual holiday periods. The scholarships will preferably be awarded to young physicians already familiar with tuberculosis problems who wish to improve their knowledge of this branch of medicine. The kind of work undertaken at the Institute will be subject to an agreement between the director and the candidate. The publication expenses resulting from this work may be defrayed partly or entirely by the Institute. The scholarships will be awarded at the summer session of the Executive Committee of the International Union, which meets this September. No candidature will be considered unless it has been forwarded by an association belonging to the International Union. The body representing Great Britain and Northern Ireland is the National Association for the Prevention of Tuberculosis, Tavistock House North, Tavistock Square, London, W.C.1, to whom applications should be sent not later than July 1st, giving particulars as to age, qualifications, and professional experience.

\section{MAGNESIUM DEFICIENCY IN THE RAT}

BY

RONALD W. BROOKFIELD, M.D., PH.D.

M.R.C.P., D.P.H.

HONORARY ASSISTANT PEIYSICIAN, ROYAL SOUTHERN HOSPITAL, LIVERPOOL ; BRITISH MEDICAL ASSOCIATION RESEARCH SCHOLAR, 1929-31

(From the Department of Biochemistry, University of Liverpool)

The intensive study of calcium metabolism, for which the investigations of rickets and tetany carried out in recent years have been chiefly responsible, has not stimulated significantly inquiry into the part played in the organism by magnesium, which so closely resembles calcium in its chemical properties. Whereas the concentration of magnesium in serum is of the order of $2 \mathrm{mg}$. per $100 \mathrm{c.cm}$. as compared with $10 \mathrm{mg}$. of calcium, its concentration in muscle, which accounts for so large a part of the body weight, is four times as great as that of calciumthat is, $20 \mathrm{mg}$. as compared with $5 \mathrm{mg}$. The distribution of the two constituents in the tissues suggests that magnesium plays a part in physiological processes not less important than that played by calcium. Nevertheless, it is only comparatively recently that magnesium has been shown to be necessary to life.

Leroy $^{1}$ found that when mice were fed on a diet containing $1.03 \mathrm{mg}$. of magnesium in 100 grams, death occurred in twenty-four to thirty-five days, and his work has been considerably amplified by Kruse, Orent, and McCollum, ${ }^{2}$ who, using a diet which contained only $0.18 \mathrm{mg}$. of magnesium in 100 grams, have studied the symptoms and some of the biochemical changes which result when rats and puppies are deprived of magnesium. Cramer,'3 by placing young rats on a diet in which the amount of magnesium was reduced to $0.632 \mathrm{mg}$. per 100 grams, showed that degenerative changes occur in the kidneys as a result of magnesium deficiency. I have been engaged on a biochemical and pathological study of magnesium deprivation, and have utilized for this purpose a small group of rats. The findings are of interest in that while the convulsive phenomena described by Kruse, Orent, and McCollum have been confirmed, the cutaneous manifestations, which are regarded by these workers as one of the distinctive features of magnesium deprivation, have been entirely absent. Moreover, histological examination of the organs has revealed marked pathological changes in the liver, as well as changes in the kidneys somewhat similar to those reported by Cramer.

\section{EXPERIMENTAL}

A diet composed of a mixture of casein, starch, butterfat, vitamins, and salts, freed from magnesium by the mothods employed by Kruse, Orent, and McCollum, was given to eight young black-and-white rats weighing from 65 to 107 grams. Four other rats, which served as controls, received the same diet with the addition of magnesium sulphate. The animals took the diet well and increased in weight for a short period. Later the weights of both test and control rats tended to remain stationary or to fall slightly. On the twenty-second day of the experiment Rat 1, which had been quiet for some days, was found dead in its cage, and two days later Rat 3 was found in a moribund condition. On the twenty-seventh day the first convulsions were observed in Rats 7 and 8, which had previously appeared entirely normal, After going round in circles for a short period Rat 8 dived under its feeding dish and went into generalized convulsions, a tonic being followed by a clonic stage. A second slighter convulsion occurred after the first. The convuisive attack of Rat 7 was milder, but otherwise similar. Both animals recovered completely 
after an hour's quiescence. Later in the same day Rat 5 had a convulsion which appeared to be induced by the noise made by the setting in motion of a vacuum pump. Two seconds later Rat 7 again went into convulsions. In both these animals the spasms were of considerable severity, and were reminiscent of insulin convulsions in the rabbit. The animals were hurled with great violence from side to side of their cages during the tonic stage. In the clonic stage they attempted to climb up the walls of their cages, but appeared to be too weak to do so. A phase of champing of the jaws followed, and afterwards the animals lay. on their flanks apparently unconscious. Rat 5 recovered quickly, but Rat 7 had a few further clonic spasms an hour later and died.

Rat 2 died on the thirty-first day after three successive attacks. The clonic stages were prolonged, the forepaws being continuously crossed, while the jaws showed champing movements with drooling of saliva. On the thirty-sixth day Rat 4 developed oedema of the paws, and had a mild convulsion ; it died after a further slight seizure five days later. Rat 8 was found dead on the thirty-eighth day, while Rat $\mathbf{5}$ died rapidly after a very mild attack on the forty-first day. These two animals, therefore, survived eleven and fourteen days after their first observed convulsion. The sole surviving test animal, Rat 6, was killed on the fiftieth day ; it was never seen in a convulsion. The control animals, which remained in good condition, were killed about the same time.

\section{Pathological Changes}

Rigor occurred very rapidly. Dissection of the rats failed to reveal any abnormality visible to the naked eye. The livers and kidneys of Rats 4, 5, and 6, and of a control rat were examined microscopically, and the writer is indebted to Dr. R. Howard Mole, pathologist to the Royal Southern Hospital, for the histological details which follow.

Livers,-In each of the test animals the cytoplasm of many of the liver cells gave the appearance of being partially disintegrated, and had taken on a honeycomb structure. This change was most widespread in Rat 6. In this animal, too, a few scattered cells showed nuclear karyorrhexis. In Rat 5 the cytoplasmic change was focal in distribution and intervening cells were normal. In Rat 4 only slight cellular change was evident.

Kidneys.-Rat 5 exhibited profound changes in both glomeruli and tubules. The capsular lumen contained a large amount of detritus, which had compressed and pushed to one side the capillary tuft. In glomeruli less severely affected the cells lining the capsule were found to be swollen and desquamated. No normal tubules were seen. The epithelium was necrotic, and nuclei were almost absent. There was no increase in connective tissue and no calcification. In Rat 6 there was a moderate amount of parenchymatous change in the tubule cells, and a similarly moderate change in the glomeruli. Rat 4 exhibited very slight glomerular and tubular change. . It is noteworthy that this was the only animal which showed any evidence of oedema during life. The renal findings resemble those of Cramer, but the degeneration is more widespread than in the sections illustrated by him. The calcification which he found so marked a feature was absent.

\section{Discussion}

The findings recorded above are in general agreement with those of Kruse, Orent, and McCollum. My own results differ, however, in one important respect. The American workers have described a state of intense hyperaemia of the skin, which preceded the onset of the convulsions by some days. Moreover, in those animals which survived for a longer period they noted thinning of the coat and other trophic changes. In the present investiga- tion no vasomotor or trophic phenomena were observed, if the oedema noted in Rat 4 be excepted. The weights of the animals were about twice as great as those of the majority of animals employed by Kruse, Orent, and McCollum. This fact doubtless accounts for the longer period which elapsed (twenty-one days or more as against their average of eighteen days), before the motor symptoms of magnesium deprivation became manifest. The American workers found that only 14 per cent. of the younger animals survived the first attack of convulsions, but that in the case of older rats the number of survivors was greater. In harmony with this observation three out of seven of the animals in the present series lived for periods of from five to fourteen days after the first attack, and may possibly have had other attacks while not under observation before they finally succumbed.

A further interesting feature was that, as the experimental period became more prolonged, the convulsions were less severe, even though fatal results ensued. Rats 4 and 5 , the last animals to succumb, each died after a very slight attack. In Rats 3 and 7 opacities were seen to form in the lens a few minutes before death, but though the eyes of all the surviving animals were examined by Mr. A. McKie Reid with the help of the slit-lamp, no pathological changes were detected, nor did any of the animals which died subsequently exhibit the premortal opacities.

The mechanism whereby the convulsions are induced naturally calls for some explanation. Kruse, Orent, and McCollum believe that they are a form of tetany. It is generally recognized that deficiency of calcium upsets the balance of ions in the tissue fluids and leads to increased irritability of the nervous system, and they contend that the effects of magnesium deficiency are of a similar character. Differences in detail between the symptomatologies of calcium and magnesium tetany they ascribe to the different degrees of irritability of the various tissues. That there are considerable differences in the manifestations of the two deficiencies is evident. In low calcium tetany the peripheral nerves are most characteristically affected, with the production of carpopedal and laryngeal spasm. In magnesium deficiency the motor phenomena appear to result from central irritation. Thus in the present investigation the convulsions came on with great suddenness, were generalized, and, when severe, left the animal unconscious for a short period. They were, in fact, typically epileptiform. In this connexion it may be noted that Meltzer and Auer ${ }^{4}$ have shown that the injection of magnesium salts causes narcosis, and if the brain is depressed by an excess of magnesium it seems not unreasonable to suppose that it will be rendered hyperexcitable by a deficiency of the same element:

Whether the lesions in the kidneys or liver have any direct relation to the convulsions cannot yet be stated with any certainty. It seems highly probable that these lesions are responsible for the changes in the blood fat and the terminal rise in the blood non-protein nitrogen which have been reported by Kruse, Orent, and McCollum. It may ultimately be found, therefore, that the convulsions are due, not to tetany, but to renal and hepatic dysfunction.

1. Convulsive phenomena occurring in rats deprived of magnesium are described.

2. The cutaneous changes reported by other workers have not been observed.

3. Acute degenerative changes have been found in the liver and kidney.

REFERENCES

${ }^{1}$ Leroy, J.: C. R. Soc. de Biol., 1926, xciv, 431.

Kruse, H. D., Orent, E. R., and McCollum, E. V.: Journ. Biol. Chem., 1932, xcvi, 519; 1933, c, 603.

${ }^{3}$ Cramer, W.: Lancet, 1932, ii, 174.

4 Meltzer, S. J., and Auer, J.: Amer. Journ. Physiol., 1905, xiv, 366. 